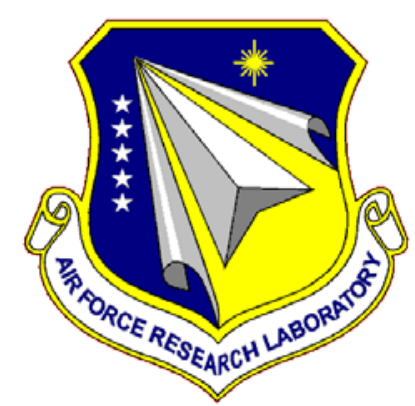

\title{
AFRL-RH-WP-TR-2014-0128
}

\section{Evaluation of the Stress Resilience Training System}

James C. Christensen ${ }^{a}$, Brian D. Everitt ${ }^{b}$, Donald Chartrand ${ }^{c}$, \& Danielle K. Boeke ${ }^{a}$

${ }^{a}$ Air Force Research Laboratory, Wright-Patterson Air Force Base, OH 45433

b Air Force Space and Missile Command, Peterson Air Force Base, CO 80914

${ }^{\mathrm{c}}$ Ease Interactive, San Diego, CA 92101

October 2014

Interim Report

Distribution A: Approved for public release; distribution unlimited.

STINFO COPY

AIR FORCE RESEARCH LABORATORY

711 HUMAN PERFORMANCE WING, HUMAN EFFECTIVENESS DIRECTORATE, WRIGHT-PATTERSON AIR FORCE BASE, OH 45433

AIR FORCE MATERIEL COMMAND

UNITED STATES AIR FORCE 


\section{NOTICE AND SIGNATURE PAGE}

Using Government drawings, specifications, or other data included in this document for any purpose other than Government procurement does not in any way obligate the U.S. Government. The fact that the Government formulated or supplied the drawings, specifications, or other data does not license the holder or any other person or corporation; or convey any rights or permission to manufacture, use, or sell any patented invention that may relate to them.

Qualified requestors may obtain copies of this report from the Defense Technical Information Center (DTIC) (http://www.dtic.mil).

\section{AFRL-RH-WP-TR-2014-0128 HAS BEEN REVIEWED AND IS APPROVED FOR PUBLICATION IN ACCORDANCE WITH ASSIGNED DISTRIBUTION STATEMENT.}

//signed//

KYLE L. TRAVER

Work Unit Manager

Applied Neuroscience Branch //signed//

SCOTT M. GALSTER

Chief, Applied Neuroscience Branch

Warfighter Interface Division

//signed//

WILLIAM E. RUSSELL

Chief, Warfighter Interface Division

Human Effectiveness Directorate

711 Human Performance Wing

Air Force Research Laboratory

This report is published in the interest of scientific and technical information exchange and its publication does not constitute the Government's approval or disapproval of its ideas or findings. 


\section{REPORT DOCUMENTATION PAGE}

Form Approved

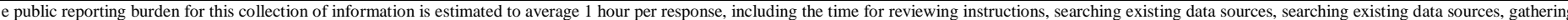

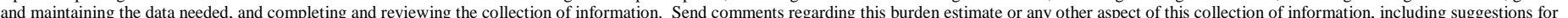

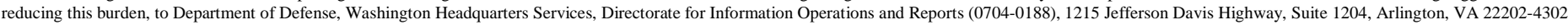

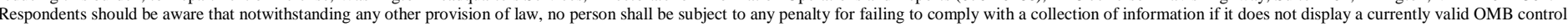
number. PLEASE DO NOT RETURN YOUR FORM TO THE ABOVE ADDRESS.

\begin{tabular}{l|c|c|}
$\begin{array}{l}\text { 1. REPORT DATE }(D D-M M-Y Y Y Y) \\
\text { 30-10-2014 }\end{array}$ & $\begin{array}{c}\text { 2. REPORT TYPE } \\
\text { Interim }\end{array}$ & $\begin{array}{c}\text { 3. DATES COVERED (From - To }) \\
1 \text { March } 2013-30 \text { April } 2014\end{array}$ \\
\hline
\end{tabular}

\section{TITLE AND SUBTITLE}

Evaluation of the Stress Resilience Training System

5a. CONTRACT NUMBER

5b. GRANT NUMBER

5c. PROGRAM ELEMENT NUMBER

6. $\operatorname{AUTHOR(S)}$

5d. PROJECT NUMBER

James C. Christensen, Brian D. Everitt, Donald Chartrand, \& Danielle K. Boeke

5e. TASK NUMBER

5f. WORK UNIT NUMBER

H0AT (53290808)

7. PERFORMING ORGANIZATION NAME(S) AND ADDRESS(ES)

Applied Neuroscience Branch, $711^{\text {th }}$ Human Performance Wing

8. PERFORMING ORGANIZATION

Air Force Research Laboratory

2510 Fifth Street, B840, W200

Wright-Patterson AFB, OH 45433-7951

9. SPONSORING/MONITORING AGENCY NAME(S) AND ADDRESS(ES)

HQ USAF Personnel Services

Air Force Resilience Office

Washington DC 20301

\section{REPORT NUMBER}

10. SPONSORING/MONITORING

AGENCY ACRONYM(S)

AF/A1S

11. SPONSORING/MONITORING

AGENCY REPORT NUMBER(S)

AFRL-RH-WP-TR-2014-0128

\section{DISTRIBUTION/AVAILABILITY STATEMENT}

Distribution A: Approved for public release; distribution unlimited.

13. SUPPLEMENTARY NOTES

88 ABW Cleared 11/24/2014; 88ABW-2014-5437. Report contains color.

14. ABSTRACT

This report describes work conducted by the Air Force Research Laboratory (AFRL), Applied Neuroscience Branch in support of the request from AF/A1S to evaluate the DARPA-funded Stress Resilience Training System, a product of the Heartmath Institute and Ease Interactive, Inc.

15. SUBJECT TERMS

neuroergonomics, mental workload, heads-up display, manned flight

\begin{tabular}{|c|c|c|c|c|}
\hline \multicolumn{3}{|c|}{ 16. SECURITY CLASSIFICATION OF: } & \multirow{3}{*}{$\begin{array}{l}\text { 17. LIMITATION } \\
\text { OF ABSTRACT: } \\
\text { SAR }\end{array}$} & \multirow{3}{*}{$\begin{array}{l}\text { 18. NUMBER } \\
\text { OF PAGES } \\
17\end{array}$} \\
\hline a. REPORT & b. ABSTRACT & c. THIS PAGE & & \\
\hline Unclassified & Unclassified & Unclassified & & \\
\hline
\end{tabular}

19a. NAME OF RESPONSIBLE PERSON (Monitor)

Kyle Traver

19b. TELEPHONE NUMBER (Include Area Code) 


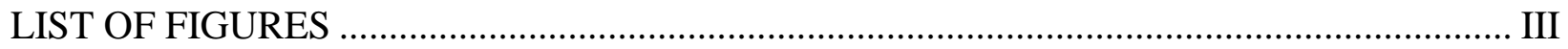

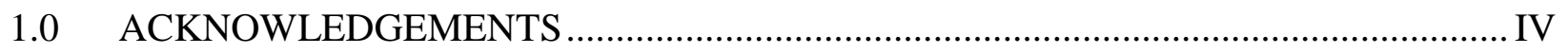

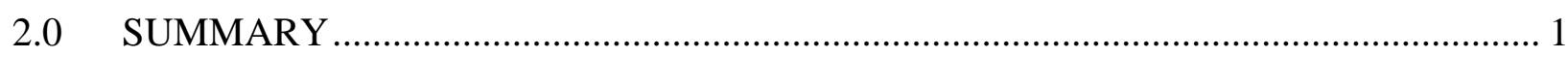

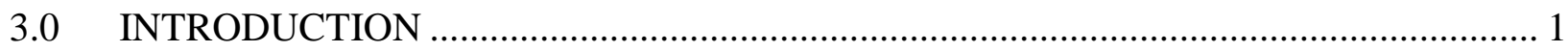

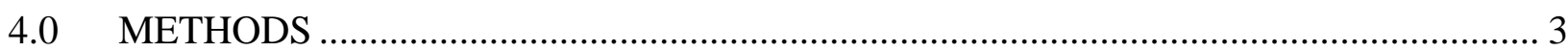

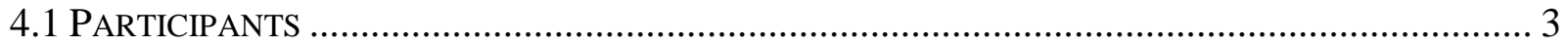

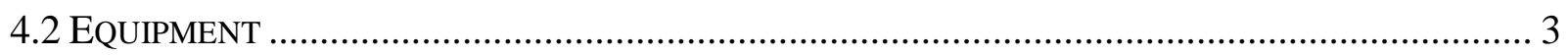

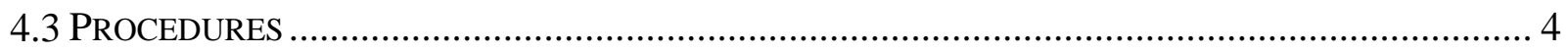

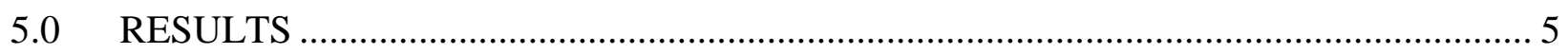

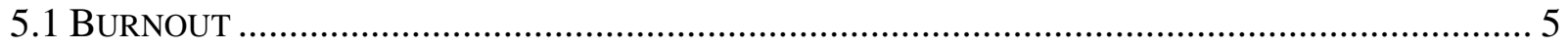

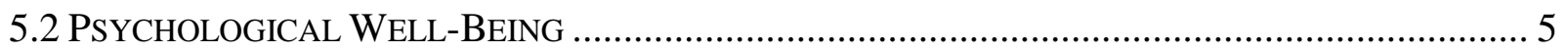

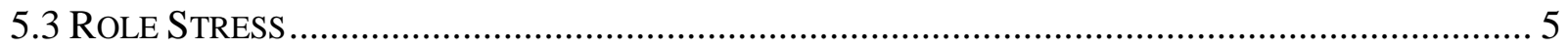

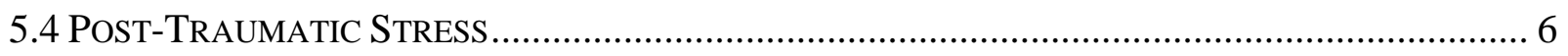

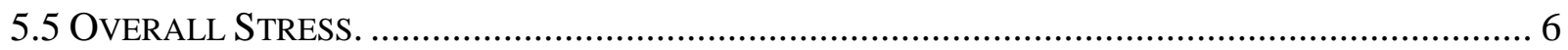

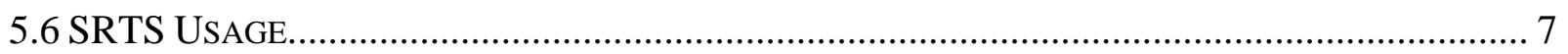

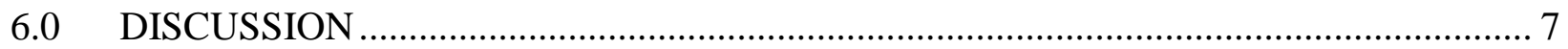

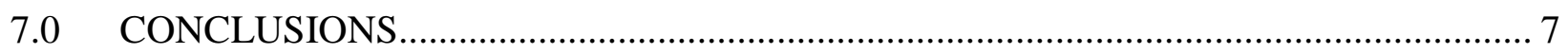

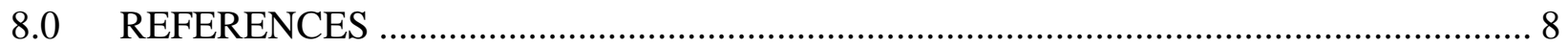

9.0 LIST OF ABBREVIATIONS AND ACRONYMS ............................................... 11 


\section{LIST OF FIGURES}

Figure

Page

1 Change in overall stress as a function of minutes of SRTS usage during the study period...... 6 


\subsection{ACKNOWLEDGEMENTS}

The authors wish to acknowledge Dr. Wayne Chappelle, Col. Kent McDonald, and Dr. Gershon Weltman for their expert assistance in the design and conduct of this evaluation. We would like to especially thank Maj. Stephen Stouder for his service and medical and research monitor during the study. Funding for the study was provided by the Air Force Resilience Office (A1SAY) and the Defense Advanced Research Projects Agency. 


\subsection{SUMMARY}

This report describes a field evaluation of the Stress Resilience Training System (SRTS), which provides a combination of cognitive learning and biofeedback-based methods to enhance resilience, delivered via classroom instruction, mentoring, and a tablet computer. The system was evaluated with a population of active duty Airmen experiencing significant occupational stress. Changes in stress, mental health, and occupational burnout were assessed before and after an eight week training period. Significant improvement in overall stress was observed; however, there were no significant changes in the other metrics. This may have been a consequence of the limited study period; however, overall participation and compliance with the training program were lower than anticipated and likely influenced results. This study therefore provides evidence supporting the efficacy of SRTS.

\subsection{INTRODUCTION}

Occupation-related stress is an unavoidable consequence of military service. The exact causes of this stress vary significantly based on location, role, and mission. Regardless of cause, the accumulation of stress over time can lead to burnout (Taris, LeBlanc, Schaufeli, \& Schreurs, 2005; Wright \& Hobfoll, 2004) and subsequent declines in mental health, particularly relating to career satisfaction and work overload (e.g. Prosser et al., 1997, Schaufeli \& Enzmann, 1998). In their 2009 study of Air Force personnel who had been deployed, Vinokur, Pierce, and Lewandowski-Romps correlated burnout with overall perceived health. They found that there is a reciprocal relationship over time between burnout and perceived health, creating the possibility of a destructive descending spiral. As a result, there is considerable need for and interest in methods and techniques that can reduce these negative outcomes or increase resilience in the face of such stress.

Psychological resilience is seen as a key component of duty fitness, particularly for units and personnel who are frequently forward deployed. Service members who are deploying for extended periods on a repeated basis face risks associated with combat that may challenge individuals' and families' coping resources (Bell, Bartone, Bartone, Schumm, \& Gade, 1997). While most military personnel and their families report coping successfully under these difficult circumstances, many also experience difficulties handling stress at some point. Studies of recent military conflicts have documented that deployment stressors and exposure to combat can result in mental health problems, including post-traumatic stress disorder (PTSD), major depression, and impairment in social functioning. Given ongoing military operations, mental disorders are likely to remain an important health care concern among combat veterans. As many as nine percent of soldiers may be at risk for mental disorders before combat deployment, and as many as 11 to 17 percent may be at risk for such disorders three to four months after their return from combat deployment (Hoge et al.,2004). As a result, service members' resilience (ability to withstand, recover, grow, and adapt under these challenging circumstances) is vital to force protection. Without such resilience, service members' performance (ability to successfully complete tasks) suffers and their fitness and readiness for deployment is adversely affected (Bates et al., 2010). There are, however, programs and strategies available to promote and support psychological resilience to stress, specifically deployment-related stress (Meredith et al., 2011). Currently available programs 
include one or more interventions drawn from a wide variety of approaches, such as positive psychology, cognitive-behavioral therapy, community-based interventions, physical fitness training, and communication skill development.

Personnel can adapt to repetitive stress and develop increased psychological resilience, a process described as stress adaptation or inoculation (Meichenbaum \& Cameron, 1989; Rosebush, 1998). Training can initiate or accelerate this process, especially with experienced military personnel who are able to control and even utilize stress productively. A key part of what experienced personnel learn is self-awareness of their stress state and self-regulation of stress effects. These skills may be enhanced by combining cognitive learning methodologies grounded in learning theory and biofeedback techniques based on heart rate variability (HRV) with simulation game-based training tools, as encapsulated in the Stress Resilience Training System (SRTS).

The visual or auditory depiction of your own physiological signals in real or near-real time has been studied for some time under the biofeedback paradigm. In this paradigm, persons learn to control signals associated with autonomic arousal by continuously observing their own signals, while engaging in mental exercises or imagery intended to reduce arousal. Biofeedback has been shown to reduce subjective stress, lower depression scores, decrease anxiety in athletes, and reduce hypertension (Siepmann et al., 2008; Baehr, Rosenfeld, and Baehr, 2001; Costa, Bonaccorsi, and Scrimali, 1984), though there also have been null results with treating PTSD in a Vietnam veteran population (Silver, Brooks, and Obenchain, 1995). This prior work substantiates that biofeedback has the potential to be an effective technique for enhancing stress resilience in military members, though likely in the context of a more comprehensive intervention.

The SRTS is based on the HeartMath cognitive learning approach with biofeedback. SRTS aims to increase compliance when delivered to a broader military population by packaging the training system in an application on a tablet computer, specifically an iPad. This application incorporates some game-based elements intended to provide intrinsic incentives for regular use. Games have been shown to enhance motivation and engagement (reviewed in Hamari, Koivisto, \& Sarsa, 2014), particularly for younger personnel who are used to gameplay in their off-duty lives. Games controlled by the user's biology (e.g., HRV-controlled games) provide a unique and highly immersive gaming experience (Prensky, 2001). These findings have been adopted in the SRTS so that trainees learn to increase HRV (indicative of reduced stress) while progressing from easy to highly challenging levels of HRV-controlled games, culminating in a racing simulation requiring fast reactions while maintaining HRV (high coherence).

While previous work has established the utility of biofeedback and the incentive potential of game-based training, this evaluation will seek to confirm or refute the combination's effectiveness in a sample of Air Force personnel experiencing significant operational and life stress. 


\subsection{METHODS}

\subsection{Participants}

Participants were all drawn from members of an Air Force Security Forces Squadron that was experiencing frequent overseas deployment rotations at the time the study was conducted. Twenty-seven participants, 23 men and 4 women, took part in the study. To preserve anonymity, exact numbers were not collected for many demographic characteristics; participants were instead asked to endorse categorical ranges. The most frequently endorsed age category was $22-25$ years (52\% of participants) with less than four years of service (52\% of participants). Most participants' ranks were E4 and below (67\% of participants) and had been assigned to their current duties for 25 months or longer (56\% of participants). All of the participants had been deployed overseas prior to the study, $15 \%$ within the preceding six months. Fifty-nine percent had been required to conduct off-base patrols or other such duties during deployment involving increased risk of combat exposure. Service members were informed of the study via email from the research team after endorsement from the squadron commander. After a group informational briefing, researchers met with each volunteer individually. Prospective participants were reminded of the purpose, duration, procedures, risks, benefits, confidentiality issues, the voluntary nature of participating, what was expected of them, and their rights as participants. These individual meetings were monitored by a neutral mental health professional who provided both research and medical oversight. Service members who agreed to participate then completed full written informed consent.

\subsection{Equipment}

Each participant was asked to complete a written inventory package that included the following structured assessments:

Burnout. Burnout was assessed with the Maslach Burnout Inventory General Survey (MBI-GS; Maslach, Jackson, \& Leiter, 1986). The MBI-GS is a well-established measure of burnout. The measure consists of three subscales: exhaustion, cynicism, and reduced professional efficacy with 5, 5, and 6 items respectively. All items are scored on a sevenpoint asymmetrical rating scale ranging from 0 ("never”) to 6 (“daily”).

Psychological Well-Being. The Outcome Questionnaire - 45.2 (OQ45, Lambert et al., 2000) was designed to be a brief and cost effective structured self-report measure of overall mental health. It is commonly used to assess clinical outcomes; however, it also provides general measures enabling the comparison of functioning across three subscales, specifically symptom distress, interpersonal relations, and social role. The OQ45 has been extensively validated (e.g. Doerfler, Addis, \& Moran, 2002; de Jong et al., 2007).

Role Stress. Role stress was assessed using fifteen items that reflect role conflict, role ambiguity, and role overload (five items each). A sample item measuring role conflict is: "I receive incompatible requests from two or more people." A sample role ambiguity item is: "I know exactly what is expected of me (reverse coded)." A sample role overload item is: "It seems like I have too much work for one person to do." Items were presented in statement format with a five point response scale ranging from 1 (Strongly Disagree) 
to 5 (Strongly Agree). Scale scores were computed by averaging items within each scale such that higher scores indicate greater endorsement of the items within the scale. The items have demonstrated adequate structural fit in a variety of cross-cultural samples (Glazer \& Beehr, 2005).

Post-Traumatic Stress. This was assessed via the PTSD Checklist, military version (PCLM; Weathers, Huska, \& Keane., 1991), a 17-item instrument that corresponds to the Diagnostic and Statistical Manual of Mental Disorders criteria (DSM-IV-TR; American Psychological Association, 2001). The PCL has demonstrated excellent psychometric properties in a variety of populations (Weathers \& Ford, 1996; Yeager, Magruder, Knapp, Nicholas, \& Frueh, 2007).

In addition to these structured assessments, the package included the basic demographic questions discussed above, simple workload ratings derived from the NASA Task Load Index (NASA-TLX; Hart \& Staveland, 1988), and a single overall subjective stress rating: "Rate the level of operational stress of your job over the past 3 months on a 0 (no stress) to 10 (extreme stress)".

Each participant was provided with an iPad preloaded with SRTS software, an ear clip heart rate sensor (photoplethysmograph) that interfaced to the iPad, and a protective case for the iPad. Entertainment functions of the iPad were disabled to accommodate usage on duty.

\subsection{Procedures}

Following the completion of written informed consent, participants were then provided with the questionnaire packet. After completing the packet, participants were assigned to receive either a standard intervention or SRTS. Those assigned to SRTS were issued iPads and received an initial training lasting approximately 2 hours on the SRTS program and device usage, delivered by Ease Interactive personnel. The standard intervention consisted of an approximately 2 hour stress resilience briefing delivered by the base local Military/Family Life Counselor, who was instructed to maximize the effectiveness of this briefing to the best of his/her abilities. This intervention was intended to represent the current standard of care for stress resilience in the Air Force and offer a realistic comparison to the efficacy of SRTS given the possibility of placebo effects.

Participants in the SRTS group were asked to provide contact information for four telephone contacts during the study. HeartMath consultants attempted to contact each participant via phone to provide mentoring, additional education, check on progress, and address any questions or issues participants had. No equivalent formal check-in was accomplished for the standard intervention group, again to replicate the current standard of care. Participants were instructed to target their iPad training usage at 60 minutes per week, broken up ideally into three 20 -minute sessions.

Following the 8 week intervention period, all participants returned any study equipment and were invited to complete a second package of written inventories, identical to the 
first. The returned iPads provided the study team with summary usage statistics including number of times the application was launched and total duration of usage.

\subsection{RESULTS}

The proportion of prospective participants who agreed to participate in the study was substantially lower than originally anticipated at approximately $20 \%$ of eligible personnel assigned to the unit. This constrained both the power of the study and the assignment to groups. Group assignment was heavily weighted toward the SRTS group to facilitate detection of pre/post changes at the cost of the power of the between-groups comparison; 20 participants were enrolled in the SRTS condition and 7 in the standard intervention. Participant numbers were further reduced by participants who were unable to complete the follow-up assessment, most commonly due to unexpected reassignment or deployment needs. A total of 17 participants completed all phases of the study, 13 in the SRTS condition and 4 in the standard intervention condition.

\subsection{Burnout}

Results from the Malasch Burnout Inventory suggest that burnout in this population was moderately high, with $30 \%$ of participants exceeding a sum score of 20 on one or more subscales. This proportion exceeds that observed for the general Air Force population (Chappelle et al, 2013) and is comparable with highly tasked intelligence and remotely piloted aircraft (RPA) operations units. In contrast to those units, burnout in our Security Forces sample was driven largely by cynicism as opposed to emotional exhaustion or concerns about professional efficacy; the proportions exceeding cutoff for those subscales were consistent with the general Air Force population at 15\%. We did not observe any changes in the rate of personnel exceeding cutoff thresholds for burnout as a function of SRTS usage, nor did we observe significant correlations between minutes of SRTS usage and changes in burnout scores.

\subsection{Psychological Well-Being}

A total score on the OQ45.2 of 63 or greater indicates high levels of distress (Lambert et al., 2000). Eight of the 28 participants enrolled met or exceeded this threshold on the initial assessment; in the post-intervention assessment, two SRTS participants fell below threshold. Due in large part to the small groups, there were no statistically significant differences in OQ45.2 score as a function of SRTS vs. standard intervention. If the proportion of enrolled participants is reflective of OQ-45.2 scores for the unit as a whole, there is some cause for concern regarding psychological well-being as the $29 \%$ rate is well above other Air Force populations, which range from 9-15\% (Chappelle et al., 2013). Self-selection bias in choosing to participate in the study may have somewhat inflated this estimate.

\subsection{Role Stress}

The three subscales of role stress (conflict, overload, and ambiguity) were individually scored, with endorsement averaging greater than $5 / 7$ assessed as indicative of significant role stress for that dimension (Chappelle, et al., 2013). The proportion of participants exceeding this threshold for overload was quite low at $4 \%$, while ambiguity and conflict 
were more prevalent at $11 \%$ and $19 \%$, respectively. Role conflict was, therefore, identified as a significant factor in overall occupational stress, though this rate still falls well below canonical examples of high role stress such as hospital floor nurses (28\%).

\subsection{Post-Traumatic Stress}

The PTSD Checklist, military version (PCL-M) results indicated that 1 participant (4\% of the total) exceeded the cutoff threshold associated with high risk of PTSD. This participant was part of the SRTS group, and his/her score did not change significantly from pre to post assessment.

\subsection{Overall Stress}

Unidimensional overall stress ratings in the SRTS group declined from pre to post, with 12 of 13 participants (92\%) reporting the same or lower levels of overall stress. This contrasts with the standard intervention condition, where 2 of 4 participants reported same or lower levels. The mean decline was modest though significant at 1 point lower on the 10 point scale. Statistical significance was assessed via sign test, resulting in $p<.01$ for SRTS, and $\mathrm{p}=.5$ for the standard intervention. We also observed strong correlations between minutes of SRTS usage and the change in overall stress score in the SRTS group, with $\mathrm{R}^{2}=.58, p<.01$ (Figure 1 ).

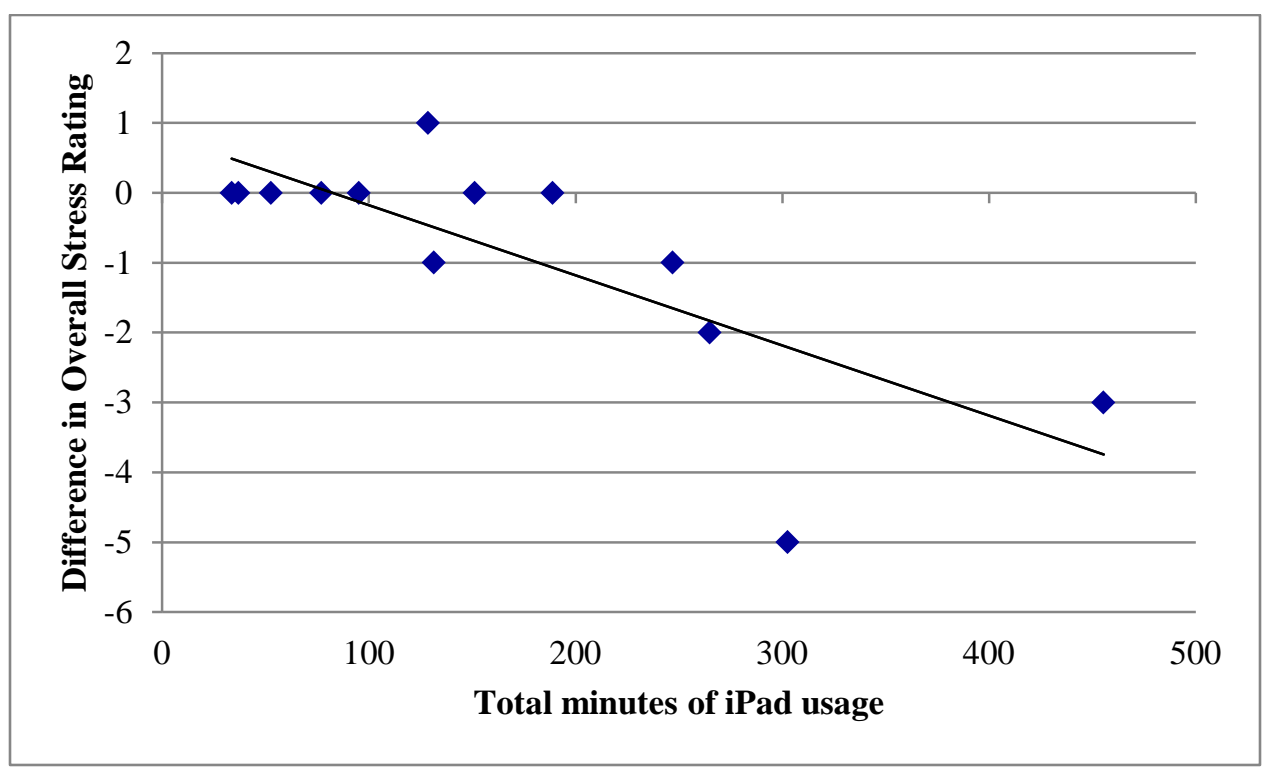

Figure 1. Change in overall stress as a function of minutes of SRTS usage during the study period. 


\subsection{SRTS Usage}

As discussed above, we observed a significant correlation between total minutes of SRTS usage and overall stress ratings, though no significant correlation with our other structured measures. Total average SRTS usage was 142 minutes per person, which was considerably lower than the requested 480 minutes (60 minutes per week over the 8 week study period). Informal feedback indicated that many participants used the iPad for a few sessions early in the study period and then discontinued usage for a variety of reasons, including low motivation and concerns about losing or damaging the devices.

\subsection{DISCUSSION}

The impact of this study was impaired by the low participation rate and the relatively low compliance amongst enrolled participants. Even with the low participation rate, we did observe positive effects on overall stress and a strong correlation with usage, which indicates that the impact of using SRTS is dose-dependent; with higher compliance, we would expect stronger positive effects.

The lack of significant impact on burnout and role stress is unsurprising. The typical time course of occupational burnout plays out over much longer periods of time than the eight week period of this study (e.g. Vinokur, Pierce, \& Lewandowski-Romps, 2009). Improved stress resilience and decreased occupational stress would be expected to positively impact burnout on the scale of one year or more. Future work with SRTS and similar systems should consider longer-term follow up assessment to test this hypothesis.

Based on these results and given the limitations already identified, we conclude that while SRTS is not a replacement for mental health support, it has significant potential for enhancing care and reinforcing physiologically-informed stress coping techniques. Compliance is a key factor and should be enhanced as much as possible via improved gamification and strong mentoring support. Consequently, we recommend SRTS usage in an environment facilitating mentor support, such as via Airman and Family Readiness Centers and/or the Medical Group. We would also reasonably expect the strongest positive effects to be observed with Airmen who are younger and highly stressed, as they are less likely to have well-developed coping skills and support networks.

\subsection{CONCLUSIONS}

Biofeedback and cognitive learning approaches to stress resilience have shown some promise, though further study and refinement of delivery mechanisms is warranted prior to consideration of large-scale deployment of systems such as SRTS. 


\subsection{REFERENCES}

Baehr, E., Rosenfeld, J. P., \& Baehr, R. (2001). Clinical use of an alpha asymmetry neurofeedback protocol in the treatment of mood disorders: Follow-up study one to five years post therapy. Journal of Neurotherapy, 4(4), 11-18.

Bates, M. J., Bowles, S., Hammermeister, J., Stokes, C., Pinder, E., Moore, M., ... \& Burbelo, G. (2010). Psychological fitness. Military Medicine, 175(8S), 21-38.

Bell, D. B., Bartone, J., Bartone, P. T., Schumm, W. R., \& Gade, P. A. (1997). USAREUR Family Support during Operation Joint Endeavor: Summary Report. Army Research Institute for the Behavioral and Social Sciences, Alexandria Va.

Chappelle, W., McDonald, K., Christensen, J., Prince, L., Goodman, T., Thompson, W., \& Hayes, W. (2013). Sources of occupational stress and prevalence of burnout and clinical distress among US Air Force cyber warfare operators (No. AFRL-SA-WP-TR-2013-0006). School of Aerospace Medicine, Wright Patterson AFB, OH.

Costa, A., Bonaccorsi, M., \& Scrimali, T. (1984). Biofeedback and control of anxiety preceding athletic competition. International Journal of Sport Psychology.

de Jong, K., Nugter, M. A., Polak, M. G., Wagenborg, J. E., Spinhoven, P., \& Heiser, W. J. (2007). The Outcome Questionnaire (OQ-45) in a Dutch population: A cross-cultural validation. Clinical Psychology \& Psychotherapy, 14(4), 288-301.

Doerfler, L. A., Addis, M. E., \& Moran, P. W. (2002). Evaluating mental health outcomes in an inpatient setting: Convergent and divergent validity of the OQ-45 and BASIS-32. The journal of behavioral health services \& research, 29(4), 394-403.

Glazer, S., \& Beehr, T. A. (2005). Consistency of implications of three role stressors across four countries. Journal of Organizational Behavior, 26(5), 467-487.

Hamari, J., Koivisto, J., \& Sarsa, H. (2014). Does Gamification Work? - A literature review of empirical studies on gamification. In proceedings of the 47th Hawaii International Conference on System Sciences, Hawaii, USA, January 6-9, 2014.

Hart, S. G., \& Staveland, L. E. (1988). Development of NASA-TLX (Task Load Index): Results of empirical and theoretical research. In P. A. Hancock, \& N. Meshkati (Eds.), Human Mental Workload. Amsterdam: North Holland Press.

Hoge, C. W., Castro, C. A., Messer, S. C., McGurk, D., Cotting, D. I., \& Koffman, R. L. (2004). Combat duty in Iraq and Afghanistan, mental health problems, and barriers to care. New England Journal of Medicine, 351(1), 13-22.

Lambert MJ, Hansen NB, Umpress V, Lunnen K, Okiishi J, Burlingame GM, et al. Administration and scoring manual for the OQ-45.2. Stevenson, MD: American Professional Credentialing Services, LLC; 2000.

Maslach, C., Jackson, S. E., \& Leiter, M. P. (1986). Maslach burnout inventory. 
Meichenbaum, D., \& Cameron, R. (1989). Stress inoculation training (pp. 115-154). Springer, US.

Meredith, L. S., Sherbourne, C. D., \& Gaillot, S. J. (2011). Promoting psychological resilience in the US military. Rand Corporation.

Prensky, M. (2001). True believers: Digital game-based learning in the military. Digital gamebased learning.

Prosser, D., Johnson, S., Kuipers, E., Szmukler, G., Bebbington, P., \& Thornicroft, G. (1997). Perceived sources of work stress and satisfaction among hospital and community mental health staff, and their relation to mental health, burnout and job satisfaction. Journal of Psychosomatic Research, 43(1), 51-59.

Rosebush, P. A. (1998). Psychological intervention with military personnel in Rwanda. Military Medicine, 163(8), 559-563.

Schaufeli, W., \& Enzmann, D. (1998). The burnout companion to study and practice: A critical analysis. CRC press.

Siepmann, M., Aykac, V., Unterdörfer, J., Petrowski, K., \& Mueck-Weymann, M. (2008). A pilot study on the effects of heart rate variability biofeedback in patients with depression and in healthy subjects. Applied psychophysiology and biofeedback, 33(4), 195-201.

Silver, S. M., Brooks, A., \& Obenchain, J. (1995). Treatment of Vietnam War veterans with PTSD: A comparison of eye movement desensitization and reprocessing, biofeedback, and relaxation training. Journal of Traumatic Stress, 8(2), 337-342.

Taris, T. W., Le Blanc, P. M., Schaufeli, W. B., \& Schreurs, P. J. (2005). Are there causal relationships between the dimensions of the Maslach Burnout Inventory? A review and two longitudinal tests. Work \& Stress, 19(3), 238-255.

Vinokur, A. D., Pierce, P. F., \& Lewandowski-Romps, L. (2009). Disentangling the relationships between job burnout and perceived health in a military sample. Stress and Health, 25(4), 355-363.

Weathers, F., Huska, J., \& Keane, T. (1991). The PTSD checklist military version (PCL-M). Boston, MA: National Center for PTSD.

Weathers, F. W., \& Ford, J. (1996). Psychometric properties of the PTSD Checklist (PCL-C, PCL-S, PCL-M, PCL-PR). Measurement of stress, trauma and adaptation.

Wright, T. A., \& Hobfoll, S. E. (2004). Commitment, Psychological Well-Being and Job Performance: An Examination of Conservation of Resources (COR) Theory and Job Burnout. Journal of Business \& Management, 9(4), 389-406. 
Yeager, D. E., Magruder, K. M., Knapp, R. G., Nicholas, J. S., \& Frueh, B. C. (2007). Performance characteristics of the post-traumatic stress disorder checklist and SPAN in Veterans Affairs primary care settings. General Hospital Psychiatry, 29(4), 294-301. 


\subsection{LIST OF ABBREVIATIONS AND ACRONYMS}

AF

APA

DSM-IV-TR

HRV

MBI-GS

NASA-TLX

PCL-M

PTSD

RPA

SRTS

OQ45
Air Force

American Psychological Association

Diagnostic and Statistical Manual for Mental Disorders, $4^{\text {th }}$ ed., text revision

Heart rate variability

Maslach Burnout Inventory General Survey

National Aeronautics and Space Administration- Task Load Index

Post-traumatic stress disorder checklist, military version

Post-traumatic stress disorder

Remotely piloted aircraft

Stress Resilience Training System

Outcome Questionnaire- 45.2 